\title{
Quando há muito a se dizer: os discursos verbais no grafite palestino
}

\author{
When there is much to be said: the verbal discourse in the Palestinian graffiti
}

Cuando hay mucho que decir: discursos verbales en graffiti palestino

Vitoria Paschoal Baldin ${ }^{1}$

\begin{abstract}
Resumo: No início da utilização do grafite na região da Palestina, ao longo da Primeira Intifada, as expressões eram majoritariamente verbais. Entretanto, nas últimas décadas a ênfase tem se deslocado para comunicações visuais, desde grandes murais coloridos até pequenos stencils que se utilizam da imagem como seu principal meio comunicativo. O presente trabalho, portanto, objetiva analisar a forma pela qual as atuais expressões de grafite verbal se articulam com o contexto comunicativo mais amplo, bem como a sua associação com as demais expressões de grafite visual. Para tanto, partiu-se da análise do registro destas comunicações, levantados a partir da bibliografia, observando os elementos discursivos que eles mobilizam. Além disso, questões linguísticas e estéticas também foram observadas. A partir disso, argumenta-se que há substancial diferença entre os discursos mobilizados pelas mensagens em árabe e em língua estrangeira, estabelecendo um público idealizado distinto.
\end{abstract}

Palavras-chave: Grafite; Discurso; Solidariedade internacional; Ativismo;

Abstract: At the beginning of the use of graffiti in the region of Palestine, during the First Intifada, this was a mostly verbal expression. However, in recent decades the emphasis has shifted to visual communications, from large colored murals to small stencils using the image as their main means of communication. The present work, therefore, aims to analyze the way in which the current expressions of verbal graffiti are articulated with the broader communicative context, as well as their association with other expressions of visual graffiti. For that, we started from the analysis of the register of these communications, raised from the bibliography, observing the discursive elements that they mobilize. Furthermore, linguistic and aesthetic issues were also noted. From this, it is argued that there is a substantial difference between the discourses mobilized by messages in Arabic and in a foreign language, establishing a distinct idealized audience.

Keywords: Graffiti; Speech; International solidarity; Activism;

Resumen: Al comienzo del uso del graffiti en la región de Palestina, durante la Primera Intifada, esta era una expresión mayoritariamente verbal. Sin embargo, en las últimas décadas el énfasis se ha desplazado a la comunicación visual, desde grandes murales de colores hasta pequeñas plantillas que utilizan la imagen como su principal medio de comunicación. El presente trabajo, por tanto, tiene como objetivo analizar la forma en que las expresiones actuales del graffiti verbal se articulan con el contexto comunicativo más amplio, así como su asociación con otras expresiones del grafiti visual. Para eso, partimos del análisis del registro de estas comunicaciones, surgido de la bibliografía, observando los elementos discursivos que movilizan. Además, también se señalaron cuestiones lingüísticas y estéticas. A partir de esto, se argumenta que existe una diferencia sustancial entre los discursos movilizados por los mensajes en árabe y en una lengua extranjera, estableciendo una audiencia idealizada distinta.

Palabras llave: Graffiti; Discurso; Solidaridad internacional; Activismo;

\footnotetext{
${ }^{1}$ Graduanda em História da Arte pela Universidade Federal de São Paulo. Atualmente, desenvolve, com apoio financeiro PIBIC-CNPq, pesquisa sobre grafite palestino e suas interlocuções.
}

Copyright (C) 2021 autor. Este é um artigo em acesso aberto distribuído nos termos da Licença Creative Commons. Atribuição que permite o uso irrestrito, a distribuição e reprodução em 


\section{Introdução}

Os grafites, de maneira geral, possuem uma relação direta com as dinâmicas presentes no espaço de seu suporte, em que esses locais também incorporam significados e conferem status simbólico a tais expressões ${ }^{2}$. Para Gitahy ${ }^{3}$, o grafite se apropria do espaço urbano de modo a discutir, recriar e imprimir a interferência humana na arquitetura da metrópole, democratizando e desburocratizando a arte, aproximando-a do homem e produzindo em espaço aberto sua galeria urbana. Assim, o espaço público é um meio especialmente eficaz para criar visibilidade enquanto questiona e negocia as dinâmicas de poder que se desenrolam naquele local.

Nesse sentido, desde o início da Primeira Intifada palestina, o grafite se tornou característica marcante na visualidade dos Territórios Palestinos Ocupados (TPO), utilizado como resposta às crescentes violências enfrentadas por essa população. No final da década de 1980, iniciou-se um movimento de resistência não-violenta inspirado por Gandhi e Martin Luther King, assumindo que métodos pacíficos ajudariam a neutralizar o poder do Estado israelense $e^{4}$ Em tal panorama, "armados de paus e pedras, jovens palestinos atacaram soldados israelenses, que reagiam à bala"5. Esse movimento, nomeado de Intifada (insurreição, levante) se prolonga até $1990^{6}$, se tornando um importante marco, em simultâneo, para a consciência nacional Palestina ${ }^{7}$ e para o desenvolvimento do grafite na região ${ }^{8}$.

Assim, após os Acordos de Oslo foi disseminada a instrução de que os grafites e murais produzidos ao longo da intifada deveriam ser apagados, sob a justificativa de que a paz deveria começar em um ambiente limpo ${ }^{9}$. Contudo, com a crescente descrença em tal processo, ainda na década de 1990, uma série de grafites estampavam nas cidades e bairros críticas às autoridades internas. Apesar disso, é apenas com a construção do Muro por Israel na Cisjordânia que a cena do grafite palestino ganha sua configuração contemporânea.

\footnotetext{
${ }^{2}$ Sarah H Awad e Brady Wagoner, Street Art of Resistance. (Cham: Palgrave Macmillan, 2017).

${ }^{3}$ Celso Gitahy, O que é graffiti? (São Paulo: Brasiliense, 2012).

${ }^{4}$ Bezen Balamir Coskun, "Power of the Words: Securitisation of the 'Other' in the Israeli-Palestinian Conflict". QUEST, v. 4 (2007).

${ }^{5}$ Keila Grinberg. O mundo árabe e as guerras árabe-israelenses. (In: Daniel Reis Filho. (org.) O Século XX. Vol. III. O tempo das dúvidas. Rio de Janeiro: Civilização Brasileira, 2000), 120.

${ }^{6}$ Mehran Kamrava, The Modern Middle East - A Political History Since the First World War. (Berkeley, Los Angeles and London: University of California Press, 2013).

${ }^{7}$ Ilan Pappé. Historia de la Palestina moderna: un territorio, dos pueblos. (Madri: AKAL, 2007).

8 Julie Peteet, "The Writing on the Walls: The Graffiti of the Intifada”. Cultural Anthropology, v. 11, n. 2 (1996).

${ }^{9}$ Bill Rolston, "Messages of allegiance and defiance: the murals of Gaza". Race \& Class, v.55, n. 4 (2014).
} 
Como consequência da Segunda Intifada palestina, sob a justificativa de proteger os israelenses dos ataques palestinos, o governo de Israel passou a adotar uma política unilateral relativa à construção de uma grande barreira física, sem considerar os recentes Acordos de Oslo, entre as comunidades $^{10}$.

Segundo o relatório, lançado em 2005, do Escritório de Coordenação das Questões Humanitárias da ONU nos Territórios Ocupados ${ }^{11}$ diversos palestinos se encontram em situação econômica difícil, tendo em vista que, em decorrência da barreira, deixaram de ter acesso a suas terras para cultivá-las, fazer a colheita ou alimentar o gado. Além disso, eles também foram isolados das escolas, universidades, hospitais e redes locais de assistência social. Comunidades foram fragmentadas e diversos locais são sufocados pelas dificuldades de circulação. Assim, o Muro produziu uma série de efeitos negativos na situação socioeconômica da Cisjordânia e também produziu grandes alterações no cenário sociocultural, reforçando os imaginários de separação. Assim,

o Muro trata da separação das famílias de suas comunidades, escolas, locais de culto, de suas clínicas, hospitais e instalações especializadas. Torna o acesso a eles, por meio de postos de controle militares, difícil, demorado e humilhante. Torna os palestinos, por assim dizer, refugiados em seu próprio país ${ }^{12}$.

É nesse sentido que a construção se tornou um dos principais suportes para o grafite produzido nos TPO. Ao longo do presente estudo, portanto, o Muro ocupou uma posição central, em que as relações e disputas de poder que se desenrolam nesse espaço estão diretamente associadas à natureza desses grafites. Os grafites produzidos atualmente nos Territórios Palestinos Ocupados são, majoritariamente, produzidos em linguagem visual. As mensagens visuais são potentes para se comunicar com públicos diversos de forma mais rápida e simples. Isto é, ainda que dependa de maior engajamento do produtor e o desprendimento, normalmente, de mais material para produzir figuras, elas possibilitam que o espectador as compreenda apenas com um relance de olhar. Apesar disso, algumas vezes, as mensagens verbais são as únicas capazes de comunicar ao leitor mensagens específicas. Por conta disso, também são observadas mensagens totalmente ou majoritariamente verbais. Em alguns casos, elas aparecem associadas a desenhos e figuras, enfatizando algum grupo - como o caso das

\footnotetext{
${ }^{10}$ René Backmann, Um muro na Palestina. (Rio de Janeiro: Record, 2012)

${ }^{11}$ René Backmann, op. cit.

12 William Parry. Against the Wall: The Art of Resistance in Palestine. (Illinois: Lawrence Hill Books, 2011), 11-12. Tradução nossa.
} 
tags de partidos políticos —, especificando um panorama ou oferecendo um encaminhamento analítico ao espectador. Dessa forma, diferentes realidades materiais e objetivos influenciam na forma pela qual sujeitos diversos se utilizam do espaço público para disseminar suas mensagens.

Assim, o presente trabalho analisa os grafites verbais produzidos nos Territórios Palestinos Ocupados (TPO) nas últimas duas décadas (2000-2020), com o objetivo de interpretar, descrever e comparar as comunicações registradas. Utilizaremos o raciocínio dedutivo como procedimento metodológico. Nesse artigo, portanto, centraremos nossas atenções às comunicações das quais a escrita é parte essencial para a significação e conexão do espectador para com aquele grafite. A análise desses objetos parte da descrição dos mesmos, comparados com o panorama espaço-temporal do qual estão associados. Para o processo descritivo, utilizamos das proposições de $\mathrm{Kress}^{13}$ a respeito da multimodalidade, tendo em vista que muitos grafites são compostos pela associação entre texto e imagem. Elementos pautados nas lógicas de sequência, para o texto, e simultaneidade, com a imagem, serão analisados a partir dessa perspectiva. Além disso, o local de colocação da imagem também carrega significado, assim como sua associação com outros elementos naquele espaço ${ }^{14}$.

Os resultados obtidos foram organizados em quatro eixos: os três primeiros em que a ênfase da comunicação está no público transnacional e o último que está centrado na utilização do árabe, endereçado para a comunidade local. Esses eixos foram organizados em três perspectivas: (1) o público idealizado; (2) o idioma utilizado; e (3) o tema central. Assim, cabe ressaltar que o árabe foi mobilizado majoritariamente para a produção de tags ou de temas caros ao público nacional. Nesse sentido, os grafites em que a escrita árabe aparece diretamente conectada ao desenho parecem ser pensados para se comunicar para um público interno ou, ao menos, falante de árabe. Já as comunicações verbais em outros idiomas operam para um espectador mais geral, indefinido e internacional — principalmente, aquelas que se utilizam do inglês. Em alguns casos, ainda, foi possível identificar a utilização do árabe e do inglês nas mesmas comunicações, demonstrando a consciência de um público simultaneamente local e internacional.

Nesse sentido, inicialmente, discutiremos os grafites verbais que criam associações entre movimentos de luta anticolonialista e a causa palestina, em um repertório diretamente associado com as origens do grafite ao longo da Intifada. Na sequência, nos voltamos para os grafites que refletem sobre a atuação de outros agentes estatais para com a causa palestina. Então, discutiremos os grafites

\footnotetext{
13 Gunther R. Kress, Literacy in the new media age. (Psychology Press, 2003).

${ }^{14}$ Ricardo Campos, Por que pintamos a cidade? Uma abordagem etnográfica do Graffiti Urbano. (São Paulo: Fim de século, 2010).
} 
que demandam agência individual na construção de uma rede de apoio internacional em prol da causa palestina. E, finalmente, abordaremos as comunicações que possuem foco no público interno.

\section{Lutas como ponto de referência transcultural}

Os grafites produzidos sobre o Muro da Cisjordânia são, em grande parte, compostos pela associação de figuras e textos produzidos em inglês, espanhol, francês e outros idiomas internacionais. Olberg ${ }^{15}$ identificou que cerca de $90 \%$ dos grafites verbais produzidos na barreira utilizavam o inglês. Tal fato, possui relação direta com o grande fluxo turístico nessas regiões, em decorrência de questões religiosas ou políticas ${ }^{16}$. A utilização denota que o público pretendido dessas comunicações é transnacional e, em simultâneo, enfatiza a grande multiplicidade relativa à identidade de seus produtores.

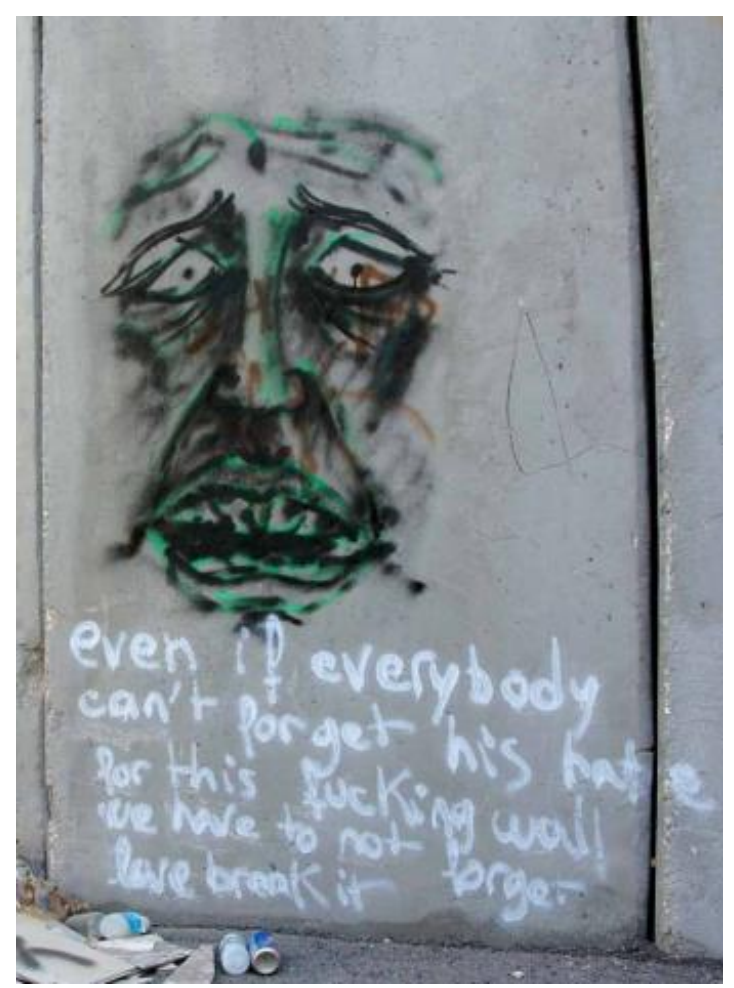

Figura 1: "Não esqueça do amor", Muro, Cisjordânia ${ }^{17}$

\footnotetext{
15 Steven T. Olberg. Political graffiti on the west bank wall in Israel / Palestine. (New York: The Edwin Mellen Press, 2013)

${ }^{16}$ Hugh Lovatt. The Aesthetics of Space: West Bank Graffiti and Global Artists.(Dissertação do Mestrado em Artes. Culture and Society of the Near and Middle, East School of Oriental and African Studies, University of London, Londres, 2010).

${ }^{17}$ William Parry. op.cit, 53.
} 


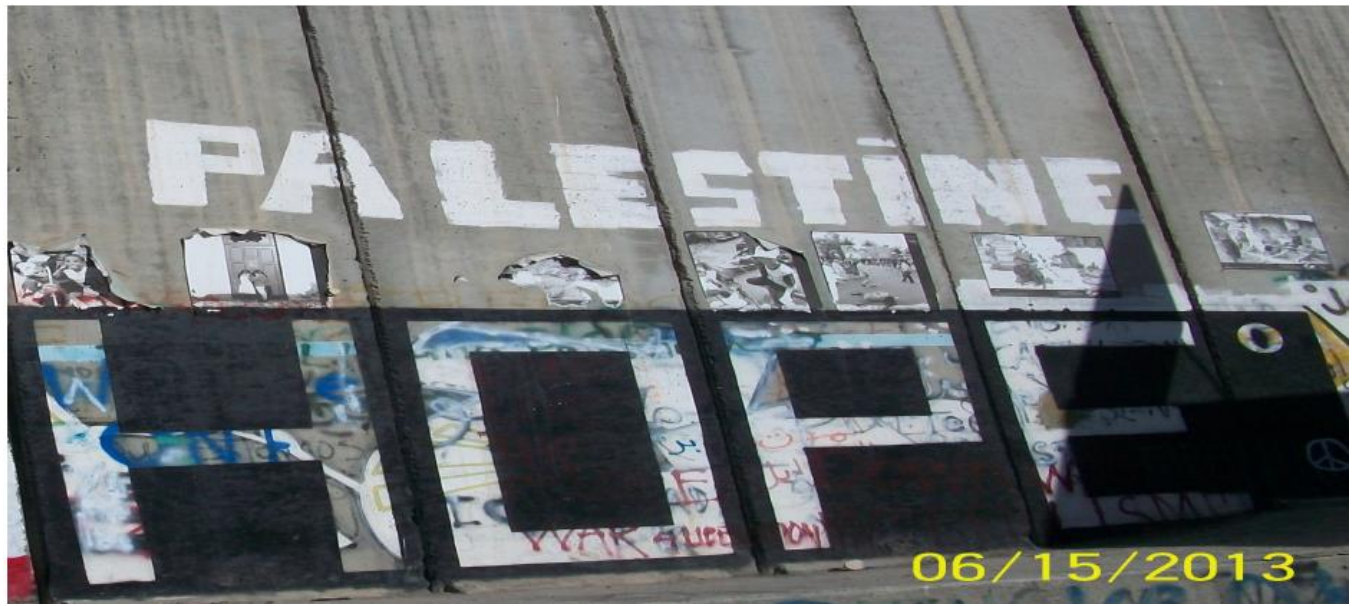

Figura 2: “Esperança Palestina”, Muro, Cisjordânia, registrado em $2013^{18}$.

Nesse sentido, a utilização desses idiomas está associada a mensagens sobre ocupação e solidariedade internacional, com incentivos às posturas relativas à paz, esperança e amor. Como a figura 1 exemplifica, podemos ler em inglês próximo ao desenho de um rosto com expressão de sofrimento: “mesmo que todos não possam esquecer o ódio dele por esse maldito Muro, nós não podemos esquecer que o amor quebra-o". A composição, junção da imagem e do texto, foi feita nas cores nacionais palestinas. Pode-se entender, portanto, que o "his hate", ódio dele, faz referência ao povo palestino. Dessa forma, enfatiza-se a necessidade de apesar de reconhecer o sofrimento afligido ao povo palestino pela construção do Muro e o ódio proveniente disso e, em simultâneo, estimular e manter sentimentos positivos como forma de lutar contra a construção. Nesse sentido, o próprio Muro é um tema para grande parte dos grafites, muitas vezes personificado como um monstro ${ }^{19}$.

De maneira análoga, na figura 2 podemos encontrar uma grande composição enfatizando a necessidade de esperança para os palestinos. Isto é, com a construção do Muro, como apontamos, representou a perda de acesso à recursos básicos, como água e hospitais. ${ }^{20}$ Assim, em alguns casos, as mensagens são mais diretas e mobilizam aspectos específicos da ocupação, como a demanda por

\footnotetext{
${ }^{18}$ Sylvia H. Dahdal. The Rhetorics of Political Graffiti on A Divisive Wall. (Tese, Doutorado em Filosofia, Arizona State University, Arizona, 2017), 103.

19 Steven T. Olberg, op. cit.

${ }^{20}$ René Backmann, op. cit.
} 
água (Figura 3). Por conta disso, a construção da barreira representou uma morte simbólica da esperança para o futuro ${ }^{21}$. Nesse sentido, uma série de grafites passam a dialogar diretamente com repertórios de esperança e busca por justiça, associado, também, ao conceito do sumud (firmeza) ${ }^{22}$ presente no ativismo palestino de maneira geral.

Ainda nesse sentido, outros movimentos de libertação popular são uma importante fonte de inspiração para o ativismo palestino, por conta disso, diversas vezes podemos encontrar citações relativas a essas mobilizações sendo estampadas sob a arquitetura urbana, especialmente na Cisjordânia. Nas figuras $4^{23}$ e 6 encontramos grafites que mobilizam citações retiradas do discurso $I$ have $a$ dream (193) de Martin Luther King que opera a partir da idealização de um futuro livre de segregação, brutalidade policial e pobreza, que será alcançada a partir de um protesto criativo e livre de violência. Nesse sentido, podemos observar como essa fala possui paralelos com a realidade enfrentada atualmente na região e, dessa maneira, passa a ser rearticulado a partir do panorama palestino.

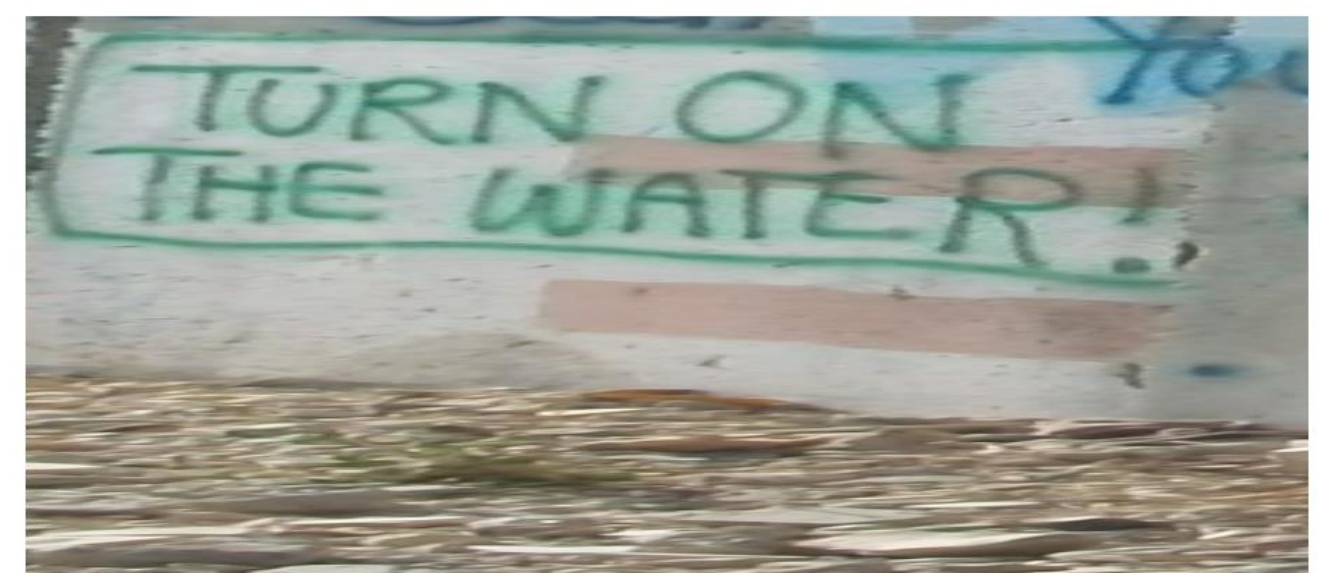

Figura 3: "Ligue a água”, Cisjordânia, registrado em 2010²4

\footnotetext{
21 Steven T. Olberg, op. cit.

${ }^{22}$ Alexandra Rijke e Toine van Teeffelen, “To Exist Is To Resist: Sumud, Heroism, and the Everyday". Jerusalem Quarterly, V. 59, N. 87 (2014).

${ }^{23}$ A figura 4 mobiliza um trecho do discurso de King baseado em Amós 5:24 na bíblia hebraica.

${ }^{24}$ Sylvia H. Dahdal, op. cit, 95.
} 


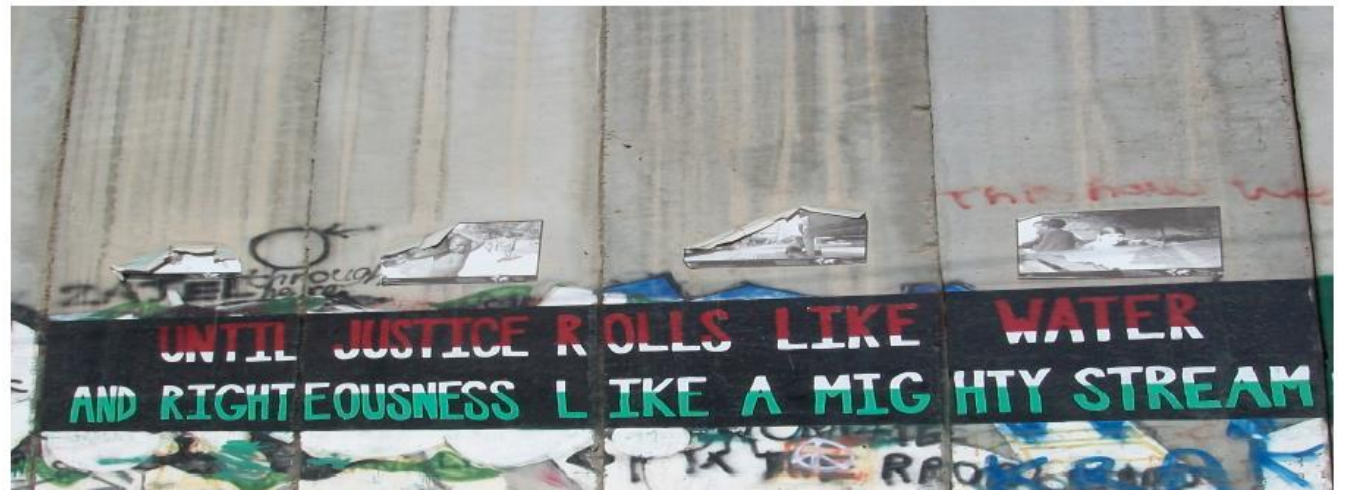

Figura 4: “Até que a justiça flua como água e a retidão como um poderoso riacho”, Muro, Cisjordânia, registrado em $2013^{25}$.

Outras citações de King também foram mobilizadas na produção de grafites, por exemplo, na figura 7. Esses grafites criam associações diretas ao Movimento pelos Direitos Civis podem ser observadas, especialmente ao mobilizarem citações que "pertencem a Martin Luther King Jr., lembrando aos telespectadores que a injustiça, o racismo e a violência ainda existem" ${ }^{26}$. De maneira semelhante, o texto Yes We Can proclamado por Obama também aparece sob as paredes nas cores palestinas (Figura 5). Abaixo da citação, '09 enfatiza a data de produção desse grafite: 2009, ano da posse de Obama à presidência dos Estado Unidos da América com uma grande esperança, não concretizada, de uma agenda que oferecesse paz aos palestinos. Nesse sentido, como Terry ${ }^{27}$ explica, após discursar na Universidade do Cairo no início de seu mandato, Barack Obama ofereceu esperanças à população da região que os Estados Unidos da América poderiam atuar como um mediador neutro para a estruturação da paz entre palestinos e israelenses. Logo no início de seu mandato, Obama chamou Mahmud Abbas, o primeiro-ministro israelense Ehud Olmert, presidente egípcio Hosni Mubarak e o rei Abdullah da Jordânia para assumir seu compromisso com o processo de paz. Em tal panorama, o grafite, ao mobilizar o pronunciamento, comunica sobre esperança e união, observada no diálogo entre agentes internos e externos. Além disso, tais comunicações enfatizam que as ideias de liberdade, justiça, paz, dignidade humana, segurança e igualdade são valores compartilhados entre os palestinos e o público transnacional mais amplo.

\footnotetext{
25 Ibid., 91.

${ }^{26}$ Sylvia H. Dahdal, op.cit, 90. Tradução nossa.

27 Janice J. Terry, "Unrequited Hope: Obama and Palestine." Arab Studies Quarterly 39.3 (2017).
} 


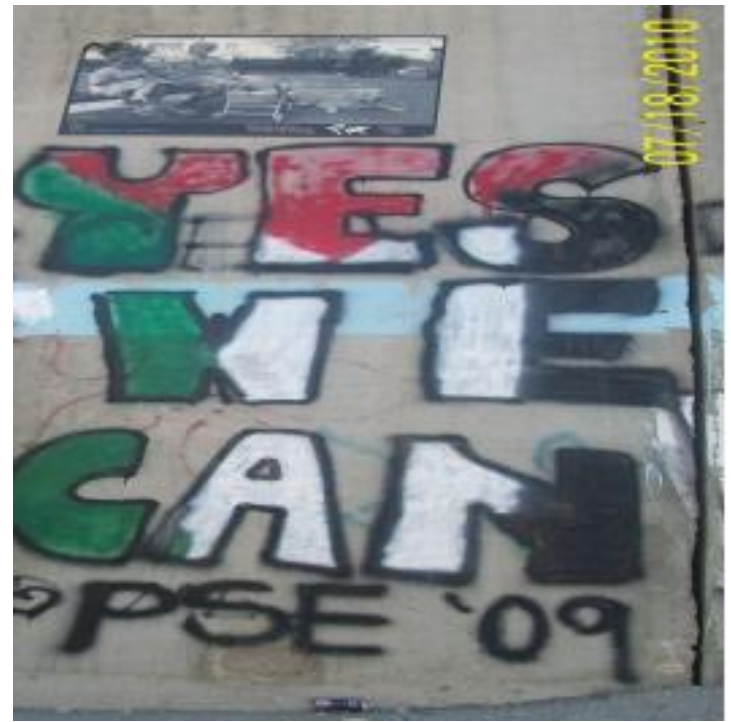

Figura 5: “Sim, nós podemos”, Muro, Cisjordânia, registrado em $2010^{28}$.

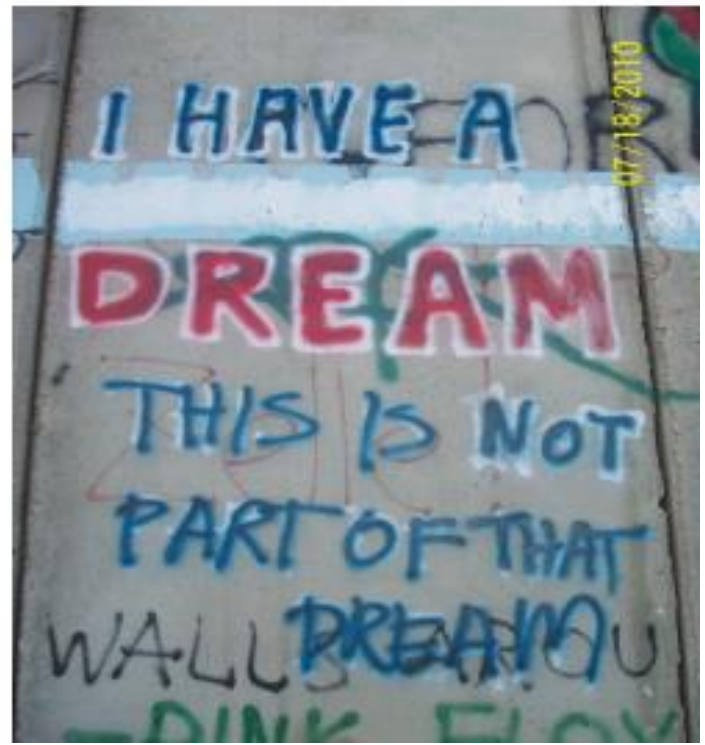

Figura 6: “Eu tenho um sonho”, Muro, Cisjordânia, registrado em $2010^{29}$.

\footnotetext{
28 Ibid., 66.

${ }^{29}$ Ibid., 66.
} 


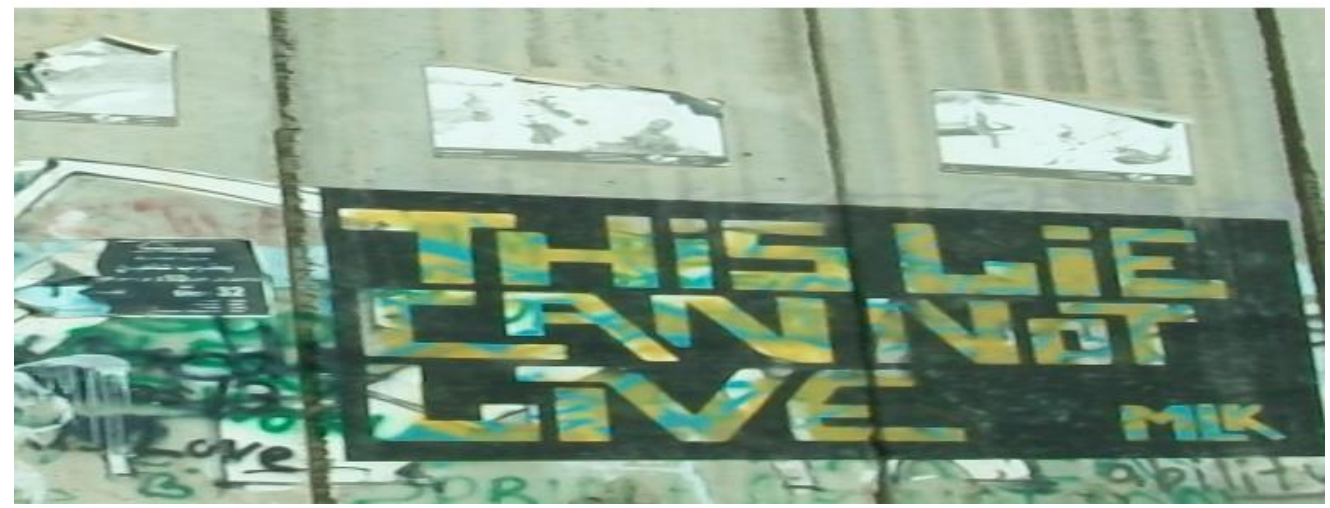

Figura 7: “Essa mentira não pode viver MLK”, Muro, Cisjordânia, registrado em 2013. ${ }^{30}$

As citações também partem de falas de outros sujeitos de destaque em movimentos sociais, políticos e culturais pacíficos. As figuras 8 e 9 exemplificam isso. A primeira se utiliza de uma frase de Nelson Mandela sobre liberdade para enfatizar o caráter predatório das negociações entre a OLP e Israel, tendo em vista o pouco poder de barganha da autoridade palestina nesse processo. Isto é, como Demant ${ }^{31}$ aponta, em 1991 ocorreram as primeiras negociações entre Israel e os Estados árabes, sinalizando o início do processo de reconhecimento mútuo entre os israelenses e a OLP. Além disso, tais negociações representaram um "ponto de encontro entre o desejo israelense de chegar em um compromisso territorial e a vontade da OLP de começar as negociações de paz" ${ }^{32}$. Apesar disso, tais negociações, contudo, impeliu a liderança palestina, com pouco poder de barganha, a aceitar qualquer coisa que Israel lhe oferecesse ${ }^{33}$. Nesse sentido, pouco tempo após os Acordos, a OLP sofreu como uma forte de descrença entre a população, especialmente, por conta da limitação de suas ações práticas nos TPO. Assim, Pappe ${ }^{34}$ argumenta que, mesmo nas negociações posteriores, Israel demonstrou sua evidente superioridade, consolidando sua posição como único capaz de impor sua vontade. Já o stencil faz menção a música Imagine de John Lennon, uma importante canção sobre paz e igualdade. Dessa forma, podemos observar que os autores desses grafites partem de um repertório internacional sobre lutas, movimentos sociais de igualdade e paz para produzir diversas comunicações. Especialmente, estabelecendo paralelos e diálogos entre a causa palestina com tais panoramas, em perspectiva didática e persuasiva.

\footnotetext{
30 Ibid., 90.

${ }^{31}$ Peter Demant, Identidades israelenses e palestinas: questões ideológicas. (In: DUPAS, Gilberto; VIGEVANI, Tullo (org.). Israel-Palestina: a construção da paz vista de uma perspectiva global. São Paulo: UNESP, 2001).

32 Ilan Pappé, op. cit., 333. Tradução nossa.

33 Peter Demant, op. cit.

34 Ilan Pappé, op. cit.
} 


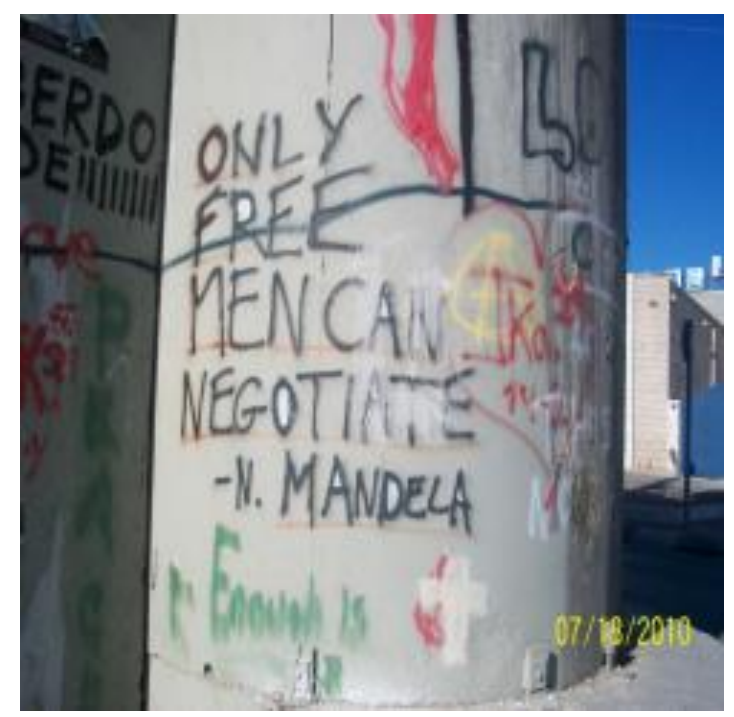

Figura 8: “Apenas homens livres podem negociar”, Cisjordânia, registrado em $2010^{35}$.

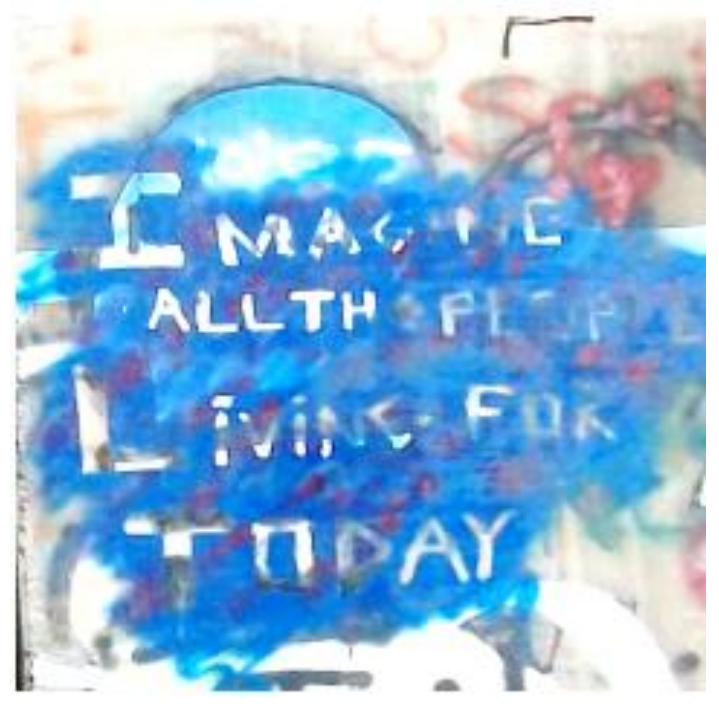

Figura 9: "Imagine”, Cisjordânia, registrado em $2013^{36}$.

Ainda nesse sentido, algumas citações fazem parte de um repertório de provérbios populares em outros países. Na figura 10 podemos ler um ditado muito popular nos países anglófonos que, apesar da indicação de autoria de Franklin, não possui um autor bem definido, fazendo parte de um repertório popular sobre mobilizações, denotando a importância de levantar-se por aquilo que se acredita. Acima da citação, ainda, podemos ler em espanhol uma frase de exaltação às lutas. De maneira

\footnotetext{
35 Ibid., 67.

36 Ibid., 67.
} 
semelhante ao que foi observado na mobilização de signos transnacionais, essas comunicações apelam para um público internacional através da utilização de repertórios mais amplos e de difusão global.

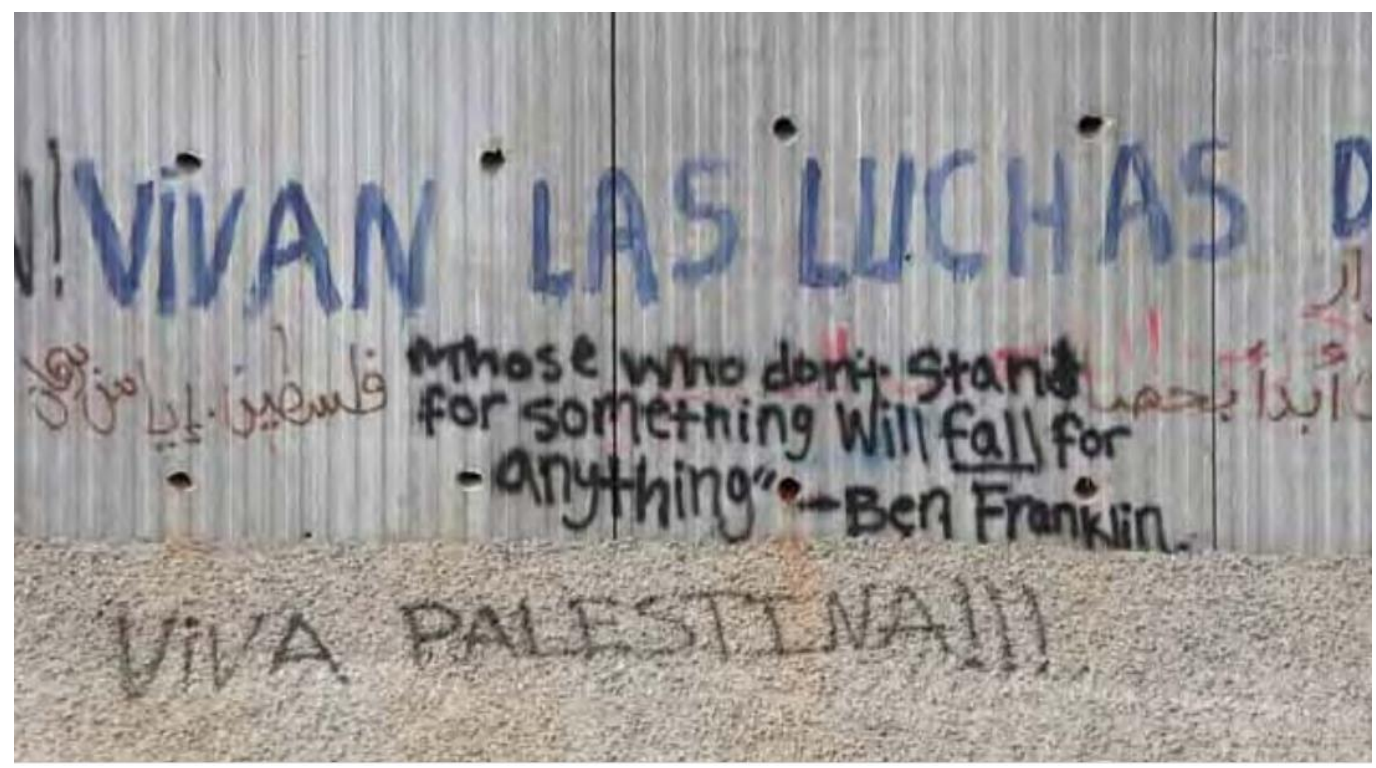

Figura 10: “Aqueles que não se erguerem por algo cairão por nada”, Cisjordânia ${ }^{37}$.

Apesar disso, podemos observar que a análise e compreensão dessas comunicações demanda certos repertórios que não necessariamente são partilhados por todos os espectadores. A indicação do autor pode auxiliar nesse processo, mas não torna a compreensão imediatamente mais acessível. Nos grafites em que a citação aparece completa o leitor precisa apenas dominar o inglês para compreendêla. Naqueles que fazem apenas menção parcial (Figura 5) a ideia central da citação não está evidenciada e demanda do espectador conhecimentos prévios ou dedicação para buscar o significado. Muitas dessas comunicações são feitas por artistas internacionais que aplicam na arquitetura palestina mensagens que conectam panoramas e processos históricos àquilo que observam no cotidiano palestino. Outras, ainda, são feitas por palestinos que vivem nesses locais e enxergam nessas citações paralelos com sua experiência. A comunicação é simultaneamente endereçada ao interno e externo, oferece e demanda apoio, conecta a luta palestina com um contexto mais amplo de mobilizações incentivando o prosseguimento delas e solicita legitimidade.

\footnotetext{
${ }^{37}$ William Parry, op. cit, 121.
} 


\section{Memória: os discursos sobre passado e legado}

O inglês também é utilizado para tecer críticas a Israel e seus aliados, especialmente aos Estados Unidos da América. Como a figura 11 evidencia, em muitos casos, as críticas são diretamente endereçadas ao país e fazem referência ao passado enfrentado pelos judeus. Essa relação entre oprimido e opressor, traçando um paralelo entre o pretérito e o futuro, vivido e protagonizado por essa população, é tema de muitas comunicações. Em outros casos, Israel é questionado sobre legado e memória, instigando a reflexão sobre as marcas negativas que serão deixadas na história por conta do conflito com os palestinos (Figura 12). Alguns grafites, ainda, utilizam-se de léxicos tabus, como palavrões, para demonstrar a grande insatisfação com a autoridade israelense (Figuras 14 e 15) ou ainda fazem comparações explícitas para com o Terceiro Reich (Figura 15).

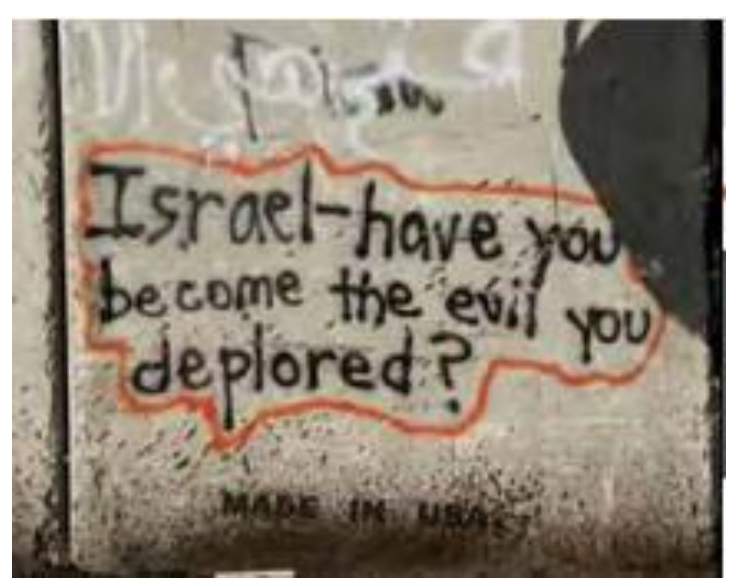

Figura 11: “Israel — você se tornou o mal que lamentou?”, Muro, Cisjordânia ${ }^{38}$.

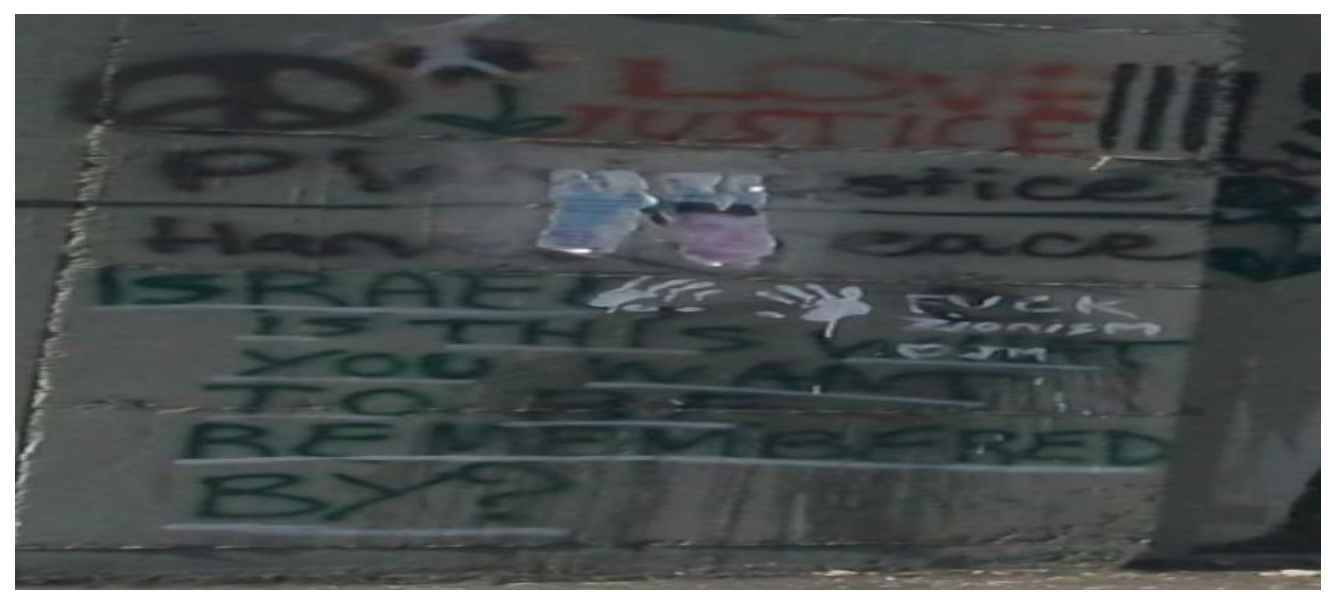

Figura 12: “Israel é assim que você quer ser lembrado?”, Muro, Cisjordânia ${ }^{39}$.

\footnotetext{
${ }^{38}$ Ibid., 121.

${ }^{39}$ Sylvia H. Dahdal, op.cit, 98.
} 


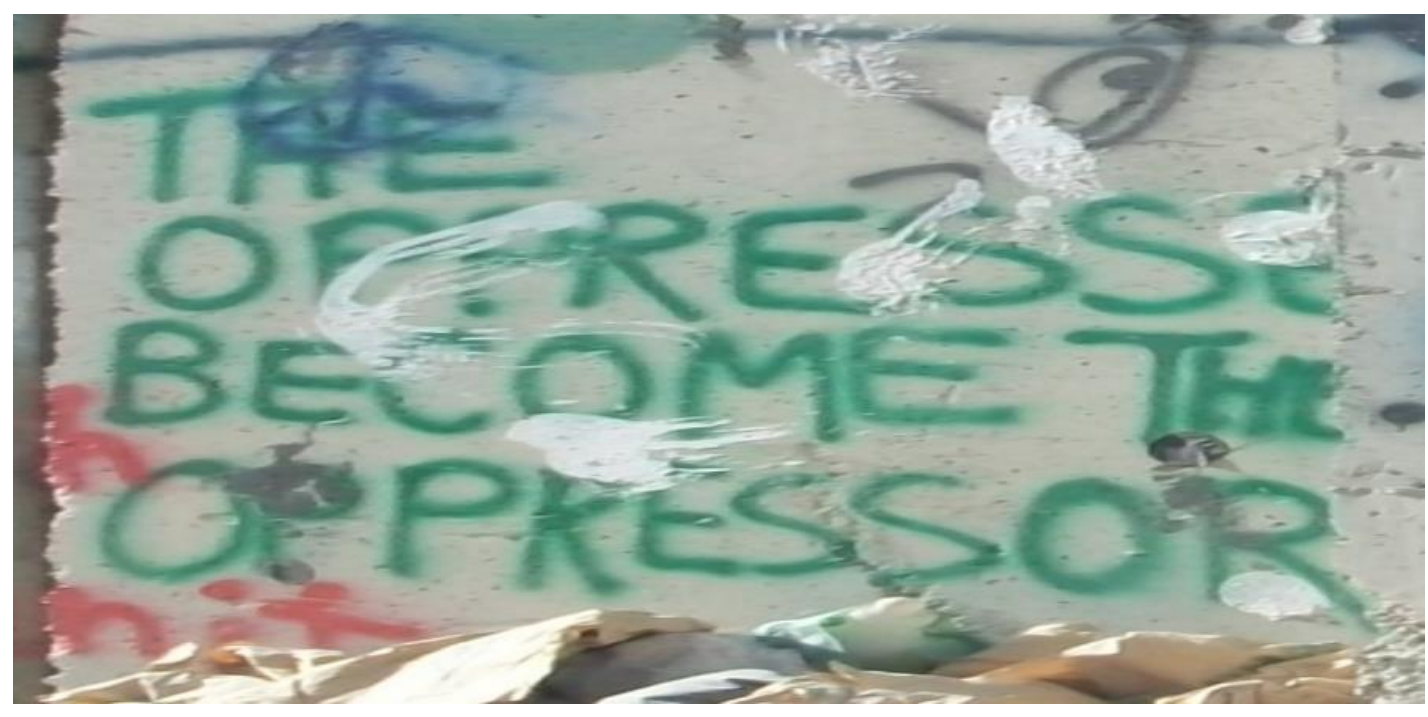

Figura 13: “O oprimido se tornou opressor”, Muro, Cisjordânia, registrado em $2010^{40}$

Como Olberg ${ }^{41}$ argumenta, o Holocausto é um termo altamente emocional e comparar o muro construído na Cisjordânia com esse evento gerou opiniões fortes. Algumas pessoas descreveram para o autor que essa comparação era "uma analogia desumanizante e sentiram que essas discussões não permitiam uma resolução porque, para muitos israelenses, o Holocausto era uma parte vívida de sua história familiar" ${ }^{\prime 2}$. Apesar disso, comunicações dessa natureza seguem sendo produzidas e registradas, principalmente no Muro da Cisjordânia, enfatizando a permanência desse discurso e imaginário nas discussões contemporâneas.

\footnotetext{
40 Ibid., 79.

${ }^{41}$ Steven T. Olberg. op. cit.

${ }^{42}$ Ibid., 153. Tradução nossa.
} 


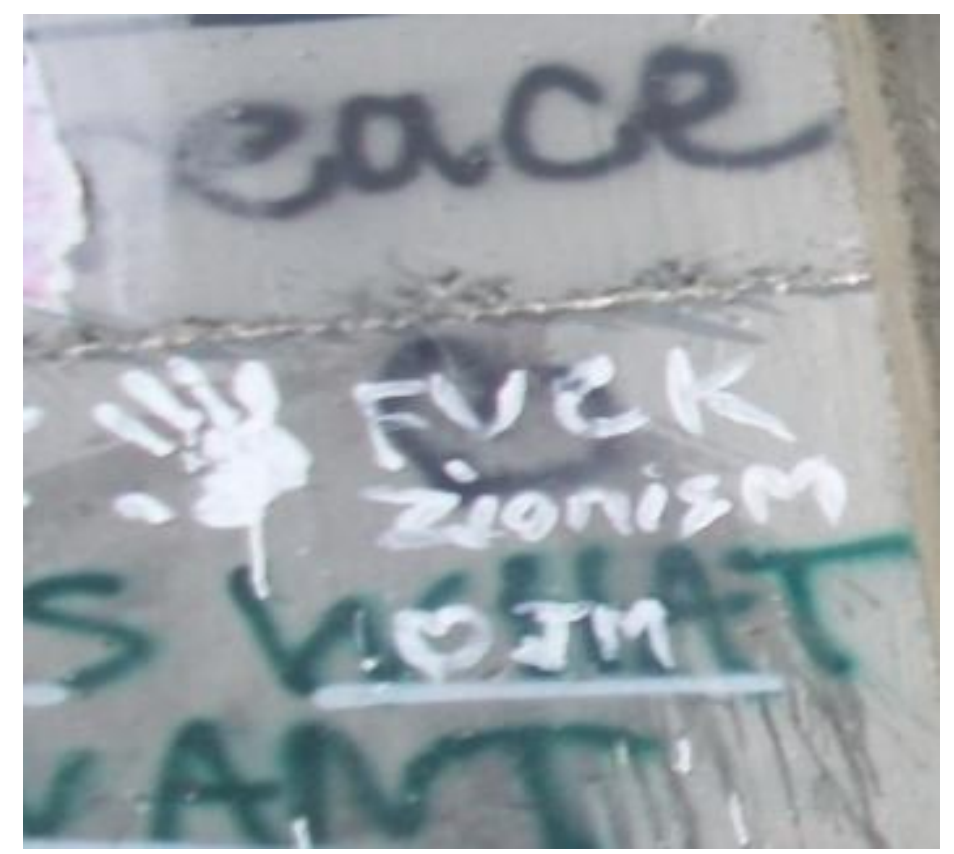

Figura 14: Léxico tabu, Muro, Cisjordânia ${ }^{43}$.

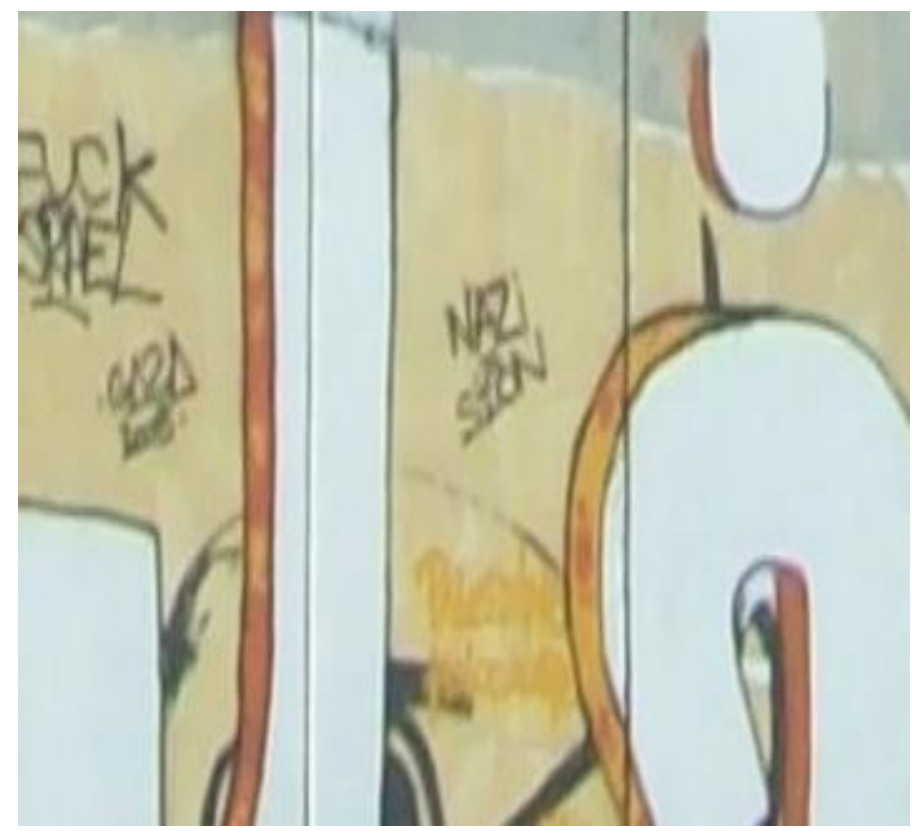

Figura 15: "Nazi Sion”, Muro, Cisjordânia.

Os grafites endereçados ao governo norte-americano fazem menção direta ao apoio financeiro e diplomático oferecido pelo país a Israel. Na figura 16 podemos observar a bandeira estadunidense pintada ao lado de uma comunicação sobre o dinheiro - tanto aquele investido pelo país de forma a auxiliar o processo de opressão, como também aquele negado aos palestinos que hoje encontram-se

${ }^{43}$ Sylvia H. Dahdal, op.cit,, 108. 
em grande estado de recessão. Assim, esses grafites “direcionam a atenção para o apoio dos EUA a Israel e resume o ódio que os locais e pró-palestinos sentem em relação os EUA"44.

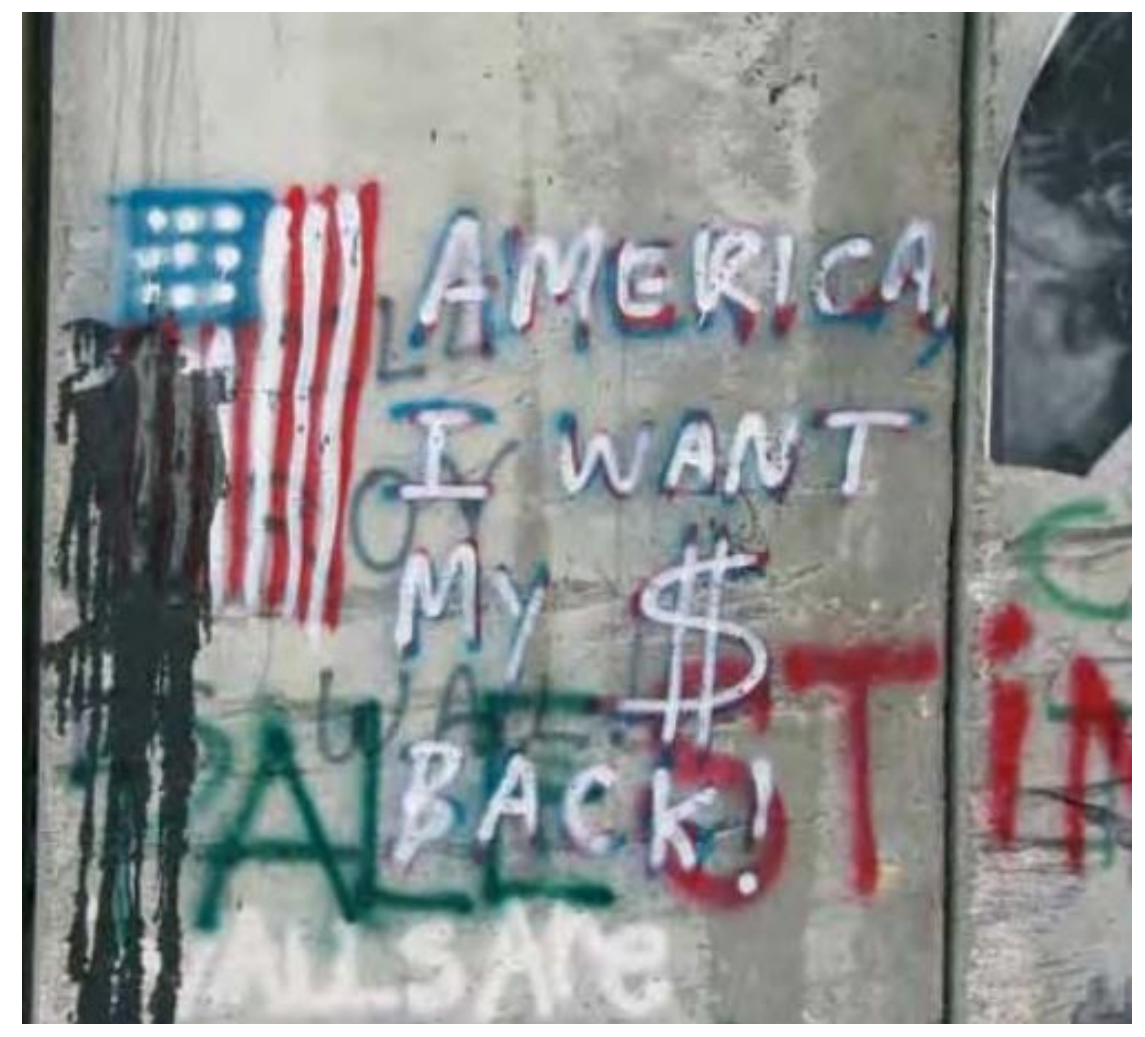

Figura 16: "América, eu quero meu \$ de volta", Muro, Cisjordânia ${ }^{45}$

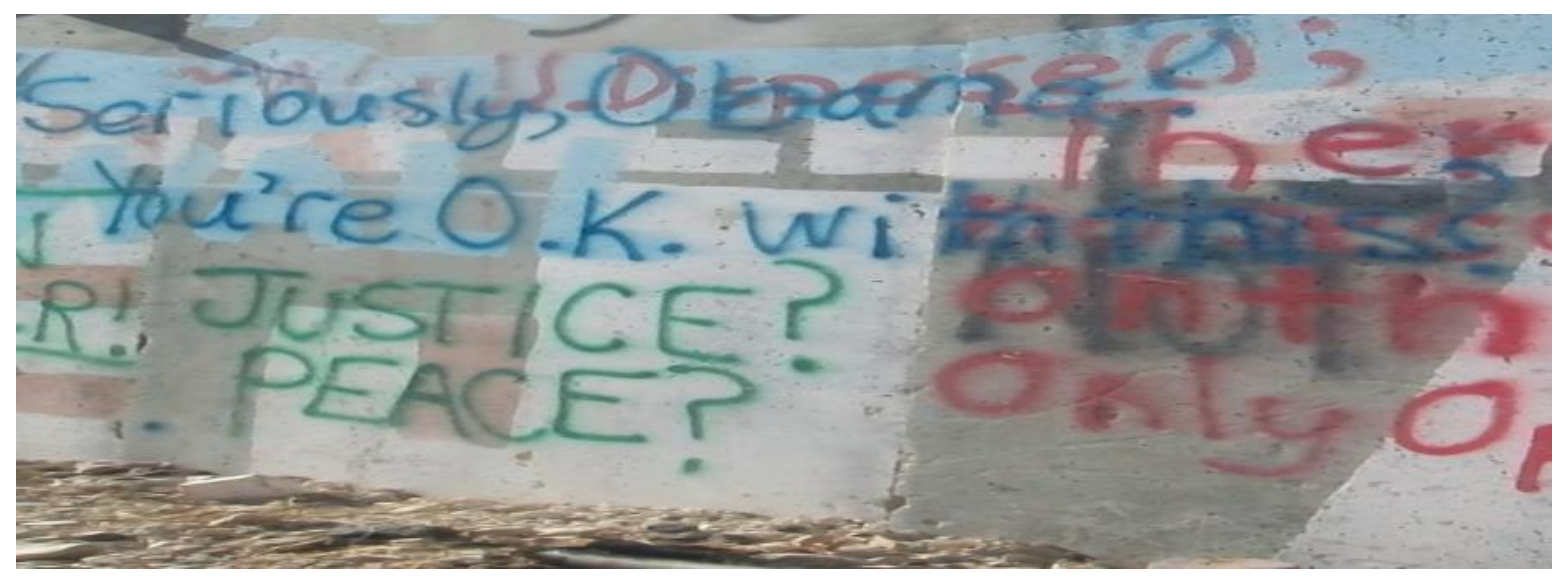

Figura 17: “Sério Obama, você está O.K. com isso?”, Cisjordânia, registrado em $2010^{46}$.

\footnotetext{
44 Ibid., 75. Tradução nossa.

${ }^{45}$ William Parry, op. cit, 62.

${ }^{46}$ Sylvia H. Dahdal, op.cit, 96.
} 


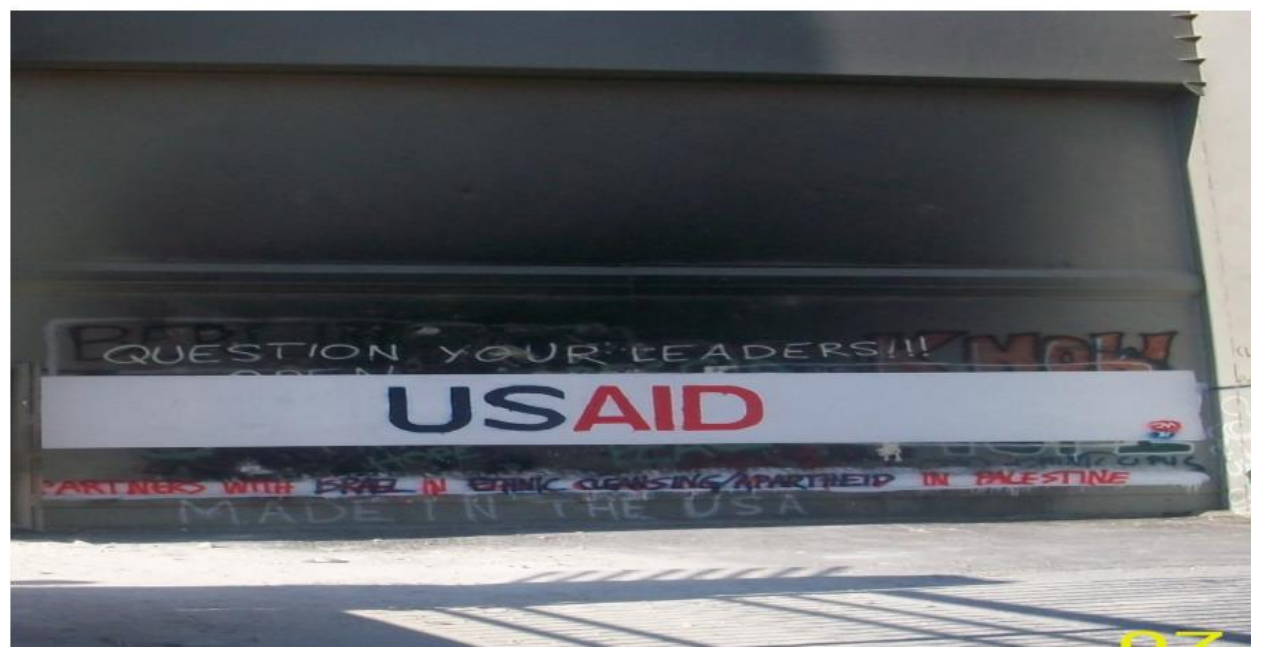

Figura 18: “USAID”, Cisjordânia, registrado em $2010^{47}$.

Outro grafite volta a fazer menção ao presidente americano do período (Figura 17), mas, distintivamente da anterior, essa mobilização não é feita baseada em sentimentos esperançosos de paz e união. Assim, apenas um ano depois da posse de Obama, a comunicação questiona a permissividade deste em relação ao panorama, contrariando as confianças nele depositadas anteriormente. Tal fato decorre do fato de que:

parece que mesmo durante seu primeiro mandato, Obama concluiu que era amplamente fútil gastar capital político na implementação de uma solução significativa de dois estados — que provavelmente não teria sucesso — e direcionou suas energias para programas domésticos que teve mais chance de sucesso $^{48}$.

Em outros casos, a relação entre os Estados Unidos e Israel aparece de uma forma mais implícita. Como na figura 18, em que se faz um jogo de palavras entre USA e aid (ajuda), enfatizando o apoio norte-americano ao sistema israelense. Acima também podemos ler: "pergunte aos seus líderes". E, também, abaixo: "parceiros com Israel na limpeza étnica/apartheid na Palestina”. Nesse sentido, é estabelecida uma relação íntima entre a opressão palestina originária das relações com Israel e o governo americano. Instiga-se, assim, que os cidadãos de países parceiros do regime israelense cobrem seus líderes por posturas políticas que demandem a mudança do cenário atual.

As relações estabelecidas entre os agentes internacionais e o panorama palestino atual enfatizam que, como Kamrava ${ }^{49}$ argumenta, o passado e o presente estão em constante dialogo. Para o autor, diversos processos iniciados na década de 1910 produzem efeitos na vida cotidiana de diversos

\footnotetext{
${ }^{47}$ Ibid., 76.

48 Janice J. Terry, op. cit., 898. Tradução nossa.

${ }^{49}$ Mehran Kamrava, op. cit.
} 
sujeitos na região ainda na contemporaneidade, em que o legado do domínio europeu ainda afeta as políticas internas e externas. Assim, tais associações carregam grande carga negativa e critica, fortemente permeada pelas experiências históricas dessa população, em que a atuação norte-americana é, diversas vezes, encarada como continuidade das violências iniciadas com o controle britânico.

\section{Solidariedade internacional}

Idiomas estrangeiros também são vastamente utilizados para demonstrar apoio à causa palestina. Tal configuração está intimamente articulada com regiões mais turísticas, como Belém e Ramalá, em decorrência do grande fluxo de turistas - provavelmente, os principais produtores desses grafites. Além do inglês, o espanhol também é um idioma bastante utilizado nos grafites observados ao longo dessa pesquisa. Algumas vezes, ele é encontrado associado a murais elaborados ou no mesmo suporte de mensagens em outros idiomas. Majoritariamente, ele é utilizado em mensagens produzidas rapidamente com spray, exaltando a luta palestina, oferecendo apoio e comparando sua opressão ao observado em outros locais. A figura 19 exemplifica isso, a violência sofrida pelos palestinos é associada a opressão de argentinos, ao lado de uma tag (JCP). O francês e o alemão também foram encontrados em alguns grafites, especialmente, sob o Muro, como, por exemplo: "paix pour la Palestine", paz para a Palestina e "ICH BIN BETHLEHEM", eu sou Belém em alemão. Em ambas as intervenções, os escritos aparecem desarticulados com os desenhos próximos a eles. 


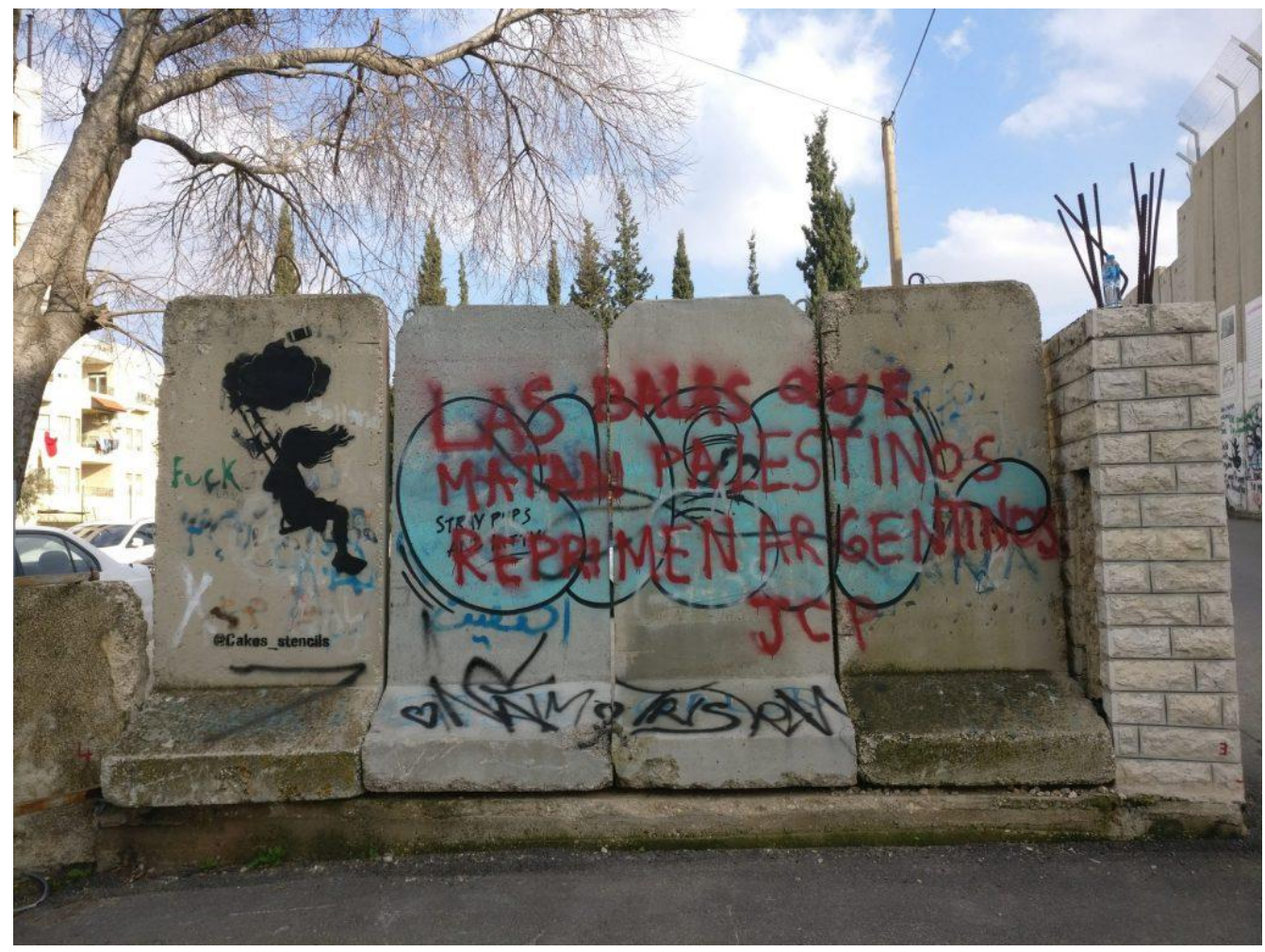

Figura 19: “As balas que matam os palestinos reprimem os argentinos JCP”, Cisjordânia ${ }^{50}$.

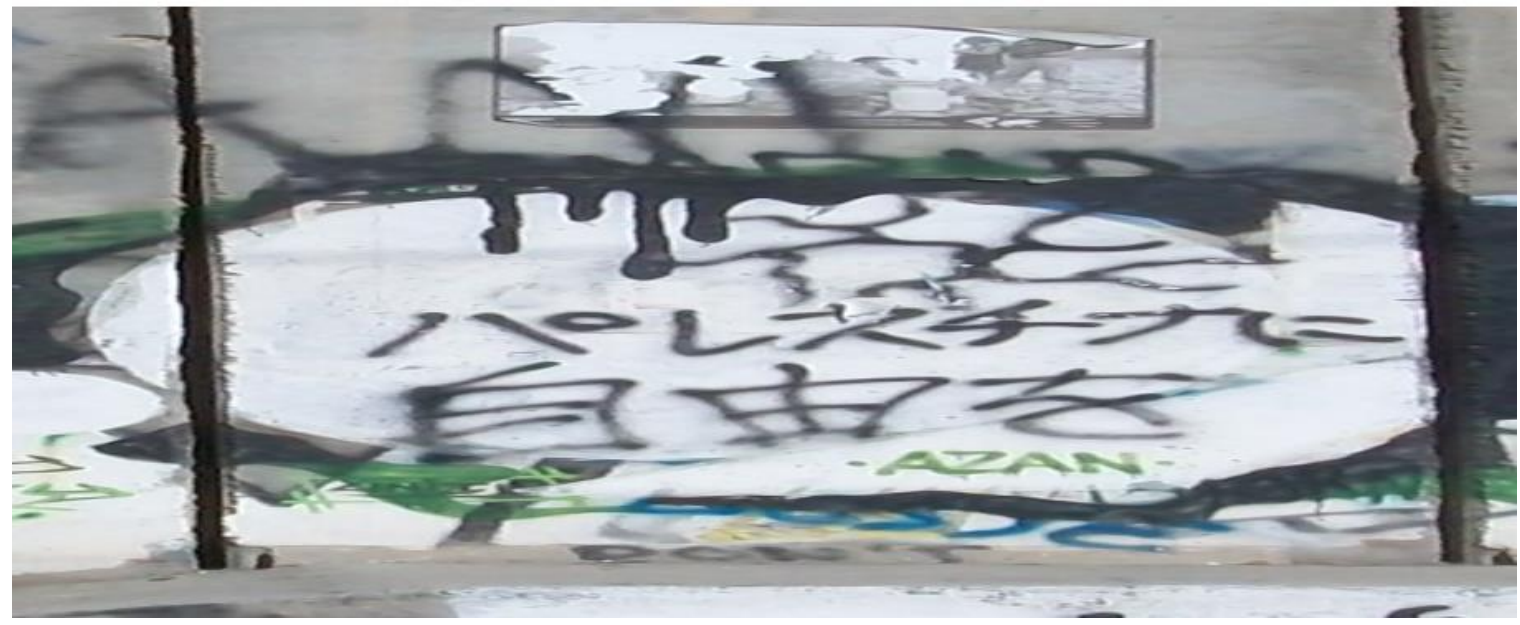

Figura 20: Grafite pedindo a libertação da terra palestina em japonês, Muro, Cisjordânia ${ }^{51}$.

De maneira semelhante, outros idiomas também foram utilizados para oferecer apoio internacional à causa nacional e as pautas relativas a isso, como a figura 20 exemplifica, em que o japonês

\footnotetext{
${ }^{50}$ Inspiringcity, "The Graffiti of the West Bank Barrier in Bethlehem". Inspirigcity. <https://inspiringcity.com/2019/01/19/the-graffiti-of-the-west-bank-barrier-in-bethlehem/>, (Acesso em 29 de setembro de 2020). ${ }^{51}$ Sylvia H. Dahdal, op.cit, 101.
} 
foi utilizado para pedir liberdade à palestina. Nesse sentido, esses repertórios evidenciam a tentativa de expressar a solidariedade de outras nações para com a Palestina, ainda que o espectador não seja, necessariamente, os palestinos. A utilização de outros idiomas aparenta ser um movimento em direção ao público internacional. Isto é, enquanto anunciam posturas solidárias à causa palestina em seu idioma nacional, ao registrarem e compartilharem essas mobilizações, estabelecem seus concidadãos como interlocutor e demandam deles uma tomada de posição em sincronia ao grafite.

\section{As comunicações para o público interno}

O árabe é utilizado em muitas expressões de grafite caligráfico, como a produção Belal Khaled exemplifica. Apesar disso, a língua também é mobilizada de formas mais simples e rápidas. Em alguns casos, o árabe aparece associado a composições visuais e oferece a elas encaminhamento analítico. Em outras comunicações a mensagem verbal é o elemento central, enquanto a figura funciona como uma espécie de acompanhamento ou ilustração. Um mural feito em Abu Dis (Figura 21) exemplifica esse processo. Nele podemos observar a cena de uma bola de futebol entrando em gol. No centro da bola (inserção), temos uma caveira com um chapéu e a sigla de um clube — E.C.F.C. Acima podemos ler: "liberdade através do futebol". Nesse sentido, o aspecto central da comunicação, feita em um local próximo a um campo de futebol, está no incentivo à prática do esporte como uma ferramenta de libertação. A figura auxilia no destaque à comunicação e ilustra o tema do grafite, além de possibilitar a inclusão de uma autoria, possivelmente, relacionada ao clube mencionado na bola. 


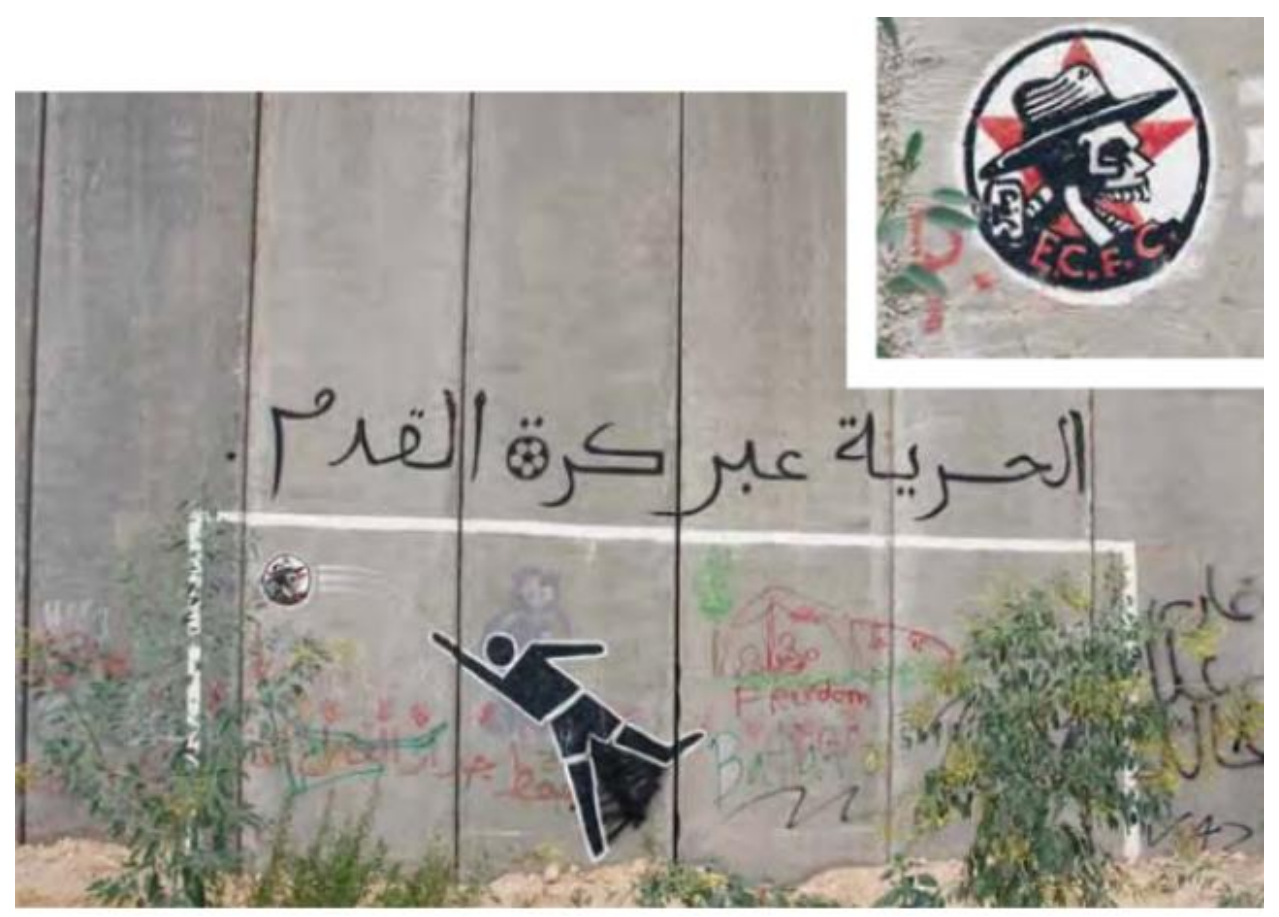

Figura 21: Grafite sobre o futebol como uma ferramenta de liberdade, Muro, Abu Dis, Cisjordânia ${ }^{52}$.

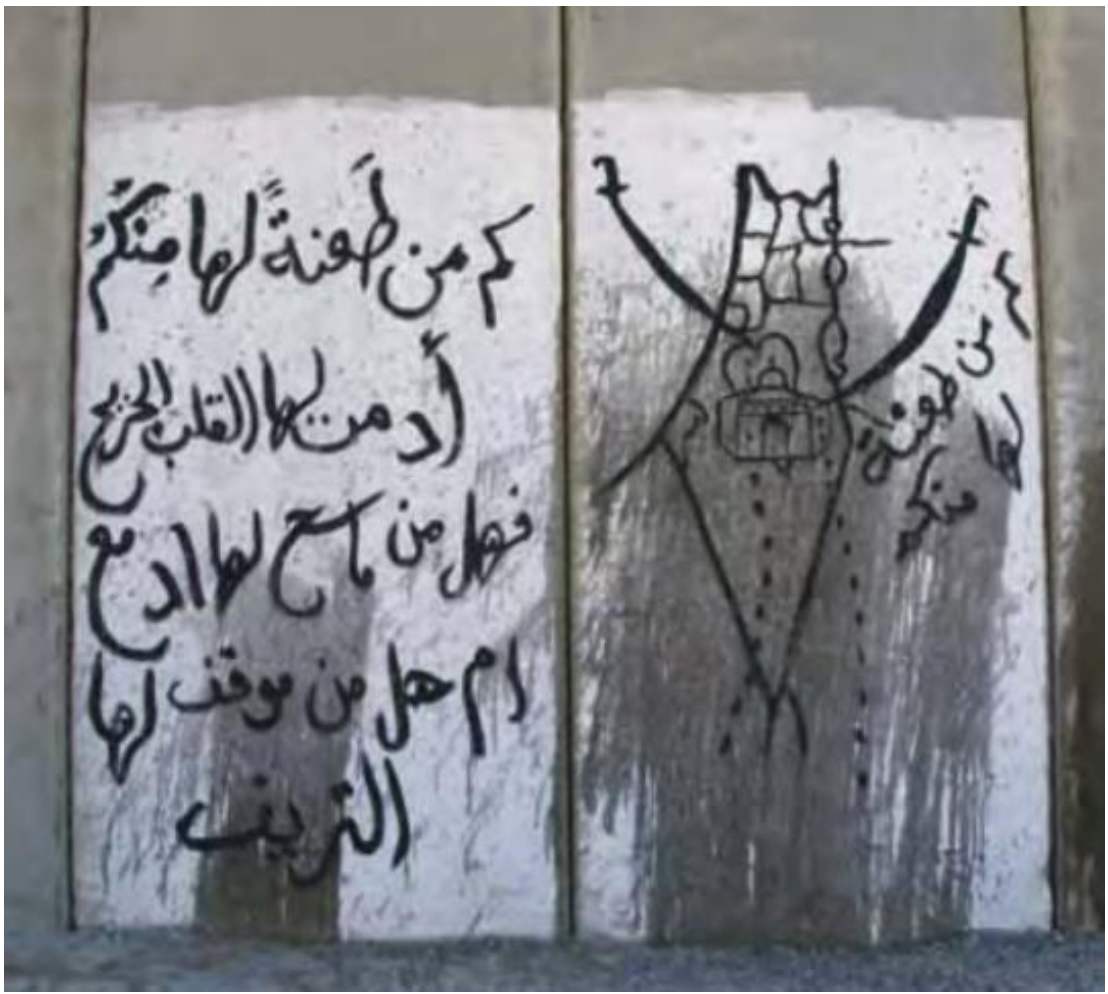

Figura 22: Poema ao lado do mapa palestino, Muro, Abu Dis, Cisjordânia ${ }^{53}$.

\footnotetext{
52 William Parry, op. cit, 153.
}

53 Ibid., 159. 
De maneira semelhante, na mesma região um poema foi escrito no Muro ao lado de um mapa palestino (Figura 22). Na poesia, podemos ler: "Quantas facadas ela sofreu de você/ que fez seu coração ferido sangrar?/ Tem alguém para enxugar as lágrimas dela/ ou parar seu sangramento?”54. Ao lado, um mapa das fronteiras palestinas pré-1948 tem duas espadas enfincadas, no centro dele há o domo da rocha. Há um evidente diálogo entre a composição e o poema, ambos operam a partir dos mesmos repertórios em uma comunicação nacionalista. O Domo da Rocha tem sido sistematicamente utilizado como um signo relativo ao nacionalismo e o ativismo palestino, em que sua importância decorre da associação entre a construção e o acesso, físico e visual, a ela que passou a ser negada aos palestinos pelo governo israelense. Além disso, a mobilização das fronteiras palestinas pré-1948 também são um elemento visual nacionalista importante para o grafite contemporâneo, tendo em vista que, como Kamrava ${ }^{55}$ aponta, as fronteiras nacionais como um elemento contestado por ambos os lados, uma das principais causas para o prosseguimento conflito. Apesar disso, uma leitura independente entre eles também possibilitaria um processo de significação satisfatório. Nesse sentido, a imagem parece operar como ilustração para o poema, semelhante ao que ocorre em livros infantis, por exemplo.

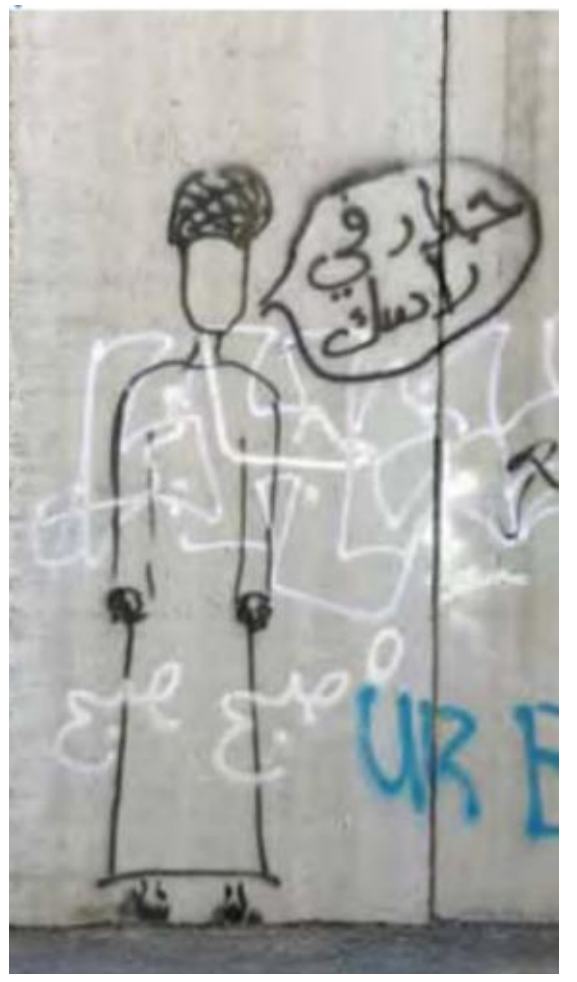

Figura 23: Grafite com balão de fala, Muro, Abu Dis, Cisjordânia ${ }^{56}$.

\footnotetext{
${ }^{54}$ Ibid., 159. Tradução nossa.

55 Mehran Kamrava, op. cit.

56 Ibid., 158.
} 
Em alguns casos, também, os textos verbais são utilizados para preencher balões de fala. $\mathrm{Na}$ figura 23, diferente do que ocorre com trabalhos analisados anteriormente, o sujeito não possui grande elaboração visual, mas a ênfase está totalmente centrada no texto escrito no centro do balão. Os únicos detalhes são uma bata e um kaffiyeh na cabeça do personagem. Podemos ler: "o Muro está em sua cabeça" 57 . Dessa maneira, o grafite, apesar de utilizar o árabe, parece endereçar-se para o público israelense.

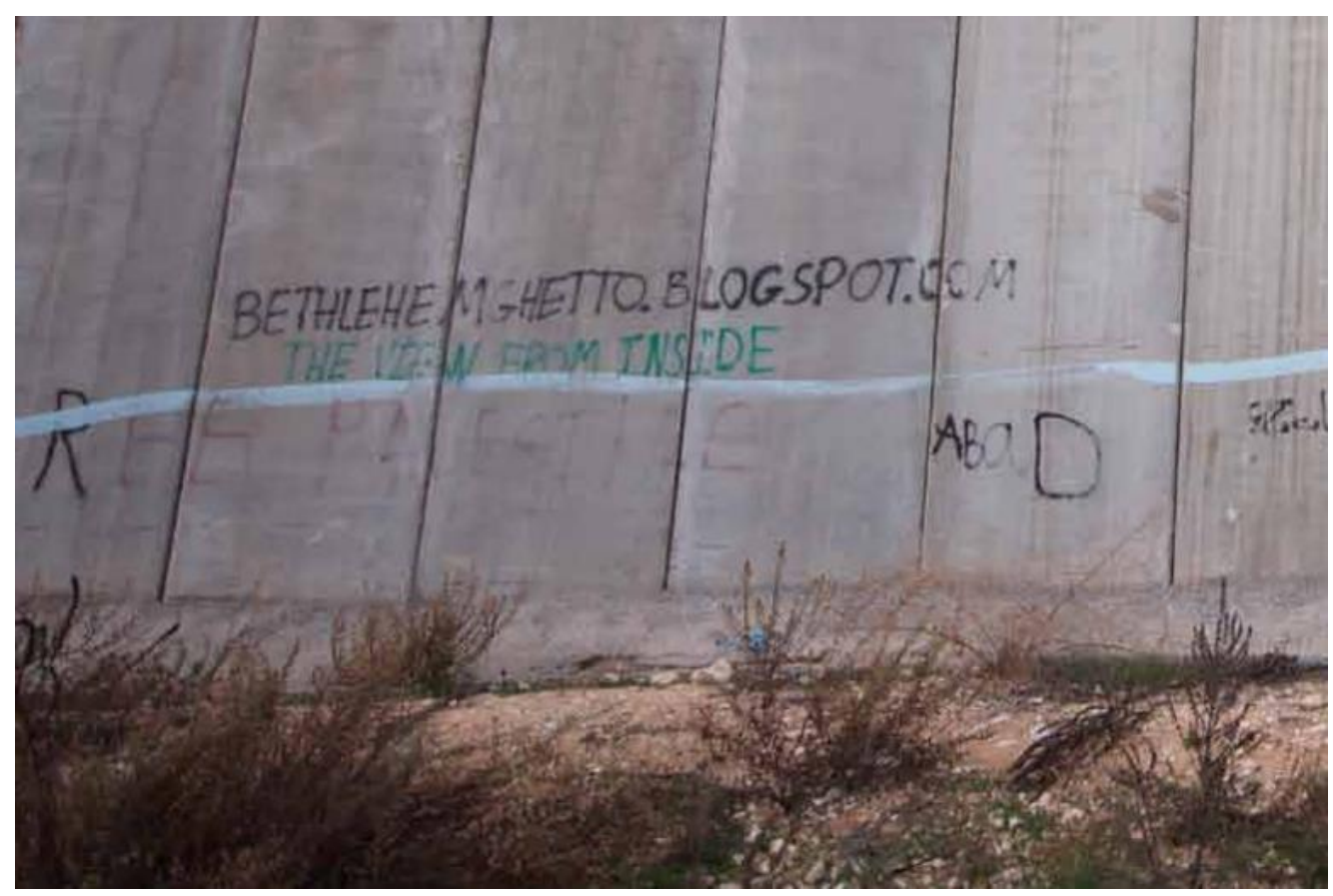

Figura 24: Endereço eletrônico sob o Muro, Cisjordânia ${ }^{58}$

Outros grafites são utilizados para fazer publicidade. Nessa perspectiva, a comunicação visual é utilizada pela rapidez de produção e a grande facilidade de acesso por parte do espectador. Para citar um exemplo, na figura 24 encontramos, em inglês, o anúncio de táxi em Belém. Algumas vezes ainda, essas publicidades não oferecem um serviço específico, mas citam sites e blogs que documentam a experiências nesses locais (Figura 24). Sua aplicação sob o Muro garante à publicidade grande visibilidade para o público, especialmente o estrangeiro. Na construção, esse tipo de anúncio é comum e ocupa os mesmos espaços de outras expressões grafitadas. Esse tipo de movimento também pode ser encarado como uma ação de resistência, tendo em vista que:

\footnotetext{
57 Ibid., 158. Tradução nossa.

${ }^{58}$ William Parry, op. cit, 153.
} 
a economia de Belém tradicionalmente dependia do turismo. Diante do Muro, os hotéis e as ruas de Belém agitavam-se durante os feriados cristãos e outras épocas de pico de turismo. Os mercados de Belém, e especialmente aqueles que cercam a Igreja da Natividade e a Gruta do Leite, estavam cheios de artefatos cristãos, especialmente aqueles itens esculpidos em madeira de oliveira de origem local, com valor simbólico para muitos cristãos. Após a construção do Muro, o turismo em Belém foi prejudicado, assim como os mercados que vendiam esses produtos $^{59}$.

Assim, ele se configura como uma tentativa de manter a estrutura econômica e preservar os meios de subsistência populacional suprimidos pela ocupação. Como Larkin ${ }^{60}$ apontou, muitos palestinos acreditam que pintar sobre o Muro suas publicidades comerciais permite que eles resistam melhor aos efeitos da própria construção, bem como da ocupação em uma perspectiva mais ampla. Dessa maneira, o carácter de resistência das comunicações estabelecidas através do grafite palestino contemporâneo extrapola as mensagens de carácter mais evidentemente político, mas também são compostas por diversas ações de ativismo cotidiano que se utilizam da arte de rua para estruturar novas formas de permanência e sobrevivência.

\section{Considerações finais}

Dessa maneira, podemos observar que o árabe é especialmente utilizado de maneira associada à elementos e discursos caros à comunidade palestina local — como o direito ao retorno, o ativismo e narrativas sobre a palestinidade. Por conta disso, ele aparece associado a diversos signos nacionais como a bandeira nacional e o Domo da Rocha. Assim, "o controle ritualizado do espaço e do tempo também se tornou um mecanismo de manutenção da identidade nacionalista e do processo discursivo que sustentava essa identidade" 61 .

Já os idiomas estrangeiros operam discursos com temas mais amplos e de relevância humanitária, diversas vezes, estabelecendo paralelos transnacionais. Essas comunicações estão especialmente centradas na transmissão de solidariedade para a causa palestina. O público idealizado dessas comunicações é transnacional. Lovatt ${ }^{62}$ argumenta que a existência de tais redes transnacionais centradas na prática e no consumo de grafite encorajam a participação e a troca entre diferentes circuitos

\footnotetext{
${ }^{59}$ Ashley Toenjes. The wall speaks: Graffiti and transnational networks in Palestine. (Tese, Mestrado em Artes, Illinois State University, Illinois, 2014), 44. Tradução nossa.

${ }^{60}$ Craig Larkin, "Jerusalem's separation wall and global message board: graffiti, murals, and the art of sumud". The Arab Studies Journal, v. 22, n. 1, Special Issue: Cultures Of Resistance (2014))

61 Steven T. Olberg. op. cit., 25-26. Tradução nossa.

${ }^{62}$ Hugh Lovatt. op. cit.
} 
socioculturais, permitindo que novas formas de engajamento -comunicativo seja estruturado em torno de pautas comuns.

As mensagens verbais, especialmente as em idiomas europeus, são encontradas majoritariamente próximas de postos de controle de grandes cidades, onde há grande circulação (inter)nacional $^{63}$. Grande parte dela está, em algum nível, associada a categorias e temas também presentes nas comunicações visuais e a utilização do idioma também está articulado com temas e abordagens específicas em relação ao conflito. Nesse sentido, podemos sintetizar que as palavras são utilizadas para oferecer às mensagens visuais um encaminhamento analítico ou adicionar-lhe novas camadas de significação, realizar a publicidade e propaganda, fazer referência a processos relativos à luta e o ativismo e demonstrar e demandar apoio internacional.

Assim, especialmente ao utilizar idiomas estrangeiros, como o inglês, o discurso tende a ter maior ênfase no ativismo pacífico, ainda que seja possível encontrar mensagens mais incisivas (como na figura 14), estas figuram a minoria das comunicações registradas. Essa postura decorre, em simultâneo, de duas questões: (1) seu comunicador é estrangeiro, tendo sua atenção especialmente voltada para a violação de direitos humanos, e comunica seu apoio à causa palestina através do inglês ou (2) seu produtor é local, mas endereça sua mensagem a um público estrangeiro e, portanto, utilizar tom mais moderado é uma estratégia que auxilia a conquista de apoio. Já a utilização do árabe é mais proeminente nos bairros e regiões menos turísticas, em que o foco central da mensagem é a própria experiência palestina e as formas pelas quais esses sujeitos podem coletivamente lidar com as diferentes violências experienciadas no cotidiano. Em ambas as frentes comunicativas, o grafite é uma expressão da vida e da experiência coletiva que atravessa o território palestino, em que o morador local, o turista ou o apoiador que entra em contato com tais mensagens através das redes sociais podem refletir sobre esse espaço, especialmente, centrado nas possibilidades de agência coletiva para a estruturação do futuro.

\section{Referências bibliográficas}

Awad, Sarah H.; Wagoner, Brady (org.). Street Art of Resistance. Cham: Palgrave Macmillan, 2017. Backmann, René. Um muro na Palestina. Rio de Janeiro: Record, 2012.

Campos, Ricardo. Por que pintamos a cidade? Uma abordagem etnográfica do Graffiti Urbano. São Paulo: Fim de século, 2010.

\footnotetext{
${ }^{63}$ Steven T. Olberg. op. cit.
} 
Coskun, Bezen Balamir. "Power of the Words: Securitisation of the 'Other' in the Israeli-Palestinian Conflict". QUEST, v. 4 (2007): 1-9.

Gitahy, Celso. O que é graffiti? São Paulo: Brasiliense, 2012.

Grinberg, Keila. O mundo árabe e as guerras árabe-israelenses. In: REIS FILHO, Daniel A. (org.) $O$ Século XX. Vol. III. O tempo das dúvidas. Rio de Janeiro: Civilização Brasileira, 2000: 97-131.

Inspiringcity, "The Graffiti of the West Bank Barrier in Bethlehem". Inspirigcity. <https://inspiringcity.com/2019/01/19/the-graffiti-of-the-west-bank-barrier-in-bethlehem/>, (Acesso em 29 de setembro de 2020).

Kamrava, Mehran. The Modern Middle East - A Political History Since the First World War. Berkeley, Los Angeles and London: University of California Press, 2013.

Kress, Gunther R. Literacy in the new media age. Psychology Press, 2003.

Larkin, Craig. "Jerusalem's separation wall and global message board: graffiti, murals, and the art of sumud”. The Arab Studies Journal, v. 22, n. 1, Special Issue: Cultures Of Resistance (2014), 134169.

Lovatt, Hugh. The Aesthetics of Space: West Bank Graffiti and Global Artists. Dissertação (Mestrado em Artes). Culture and Society of the Near and Middle, East School of Oriental and African Studies, University of London, Londres, 2010.

Olberg, Steven T. Political graffiti on the west bank wall in Israel / Palestine. New York: The Edwin Mellen Press, 2013.

Pappé, Ilan. Historia de la Palestina moderna: un territorio, dos pueblos. Madri: AKAL, 2007.

Parry, William. Against the Wall: The Art of Resistance in Palestine. Illinois: Lawrence Hill Books, 2011.

Peteet, Julie. "The Writing on the Walls: The Graffiti of the Intifada". Cultural Anthropology, v. 11, n. 2 (1996): 139-159.

Rijke, Alexandra; Teeffelen, Toine van; “To Exist Is To Resist: Sumud, Heroism, and the Everyday”. Jerusalem Quarterly, v.59, n.87 (2014).

Rolston, Bill. "Messages of allegiance and defiance: the murals of Gaza". Race \& Class, v.55, n. 4 (2014): 40-64.

Terry, Janice J. "Unrequited Hope: Obama and Palestine." Arab Studies Quarterly 39.3 (2017): 896909.

Toenjes, Ashley. The wall speaks: Graffiti and transnational networks in Palestine. Tese, Mestrado em Artes, Illinois State University, Illinois, 2014. 